\title{
Los procesos ancestrales, claves en la sostenibilidad actual
}

\section{Ancestral processes, keys to current sustainability}

\section{Valentina Cárdenas Cadena*}

(C) Recepción: $24 / 10 / 2019$

C) Aprobación: 27/11/2019

C Publicación: 19/12/2019

\section{Para citar este artículo:}

Q Cárdenas Cadena, V. (2019). Los procesos ancestrales, claves en la sostenibilidad actual. Indagare, (7), 76-80. https://doi.org/10.35707/ indagare/710

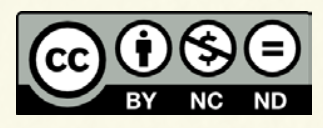

* Estudiante del programa de Comunicación Social y Periodismo de la Universidad de Ibagué. ORCID: 0000-0001-85696745. cardenas.valentina0@gmail.com 


\title{
Resumen
}

Hoy en día, muchos de los contextos rurales se han visto invadidos por la construcción de infraestructuras que no se piensan para los lugares en donde son desarrolladas. Además, se dejan de lado los saberes y prácticas ancestrales. En la Universidad de Ibagué se genera un espacio de reflexión frente a estos procesos.

\begin{abstract}
Today, many of the rural contexts have been invaded by the construction of infrastructures that are not intended for the places where they are developed. In addition, ancestral knowledge and practices are neglected. A space for reflection regarding these processes is generated at Universidad Ibagué.
\end{abstract}

Palabras claves: Arquitectura, patrimonio, infraestructura, ruralidad, medio ambiente.

Key words: Architecture, heritage, infrastructure, rurality, environment.

Todo inicia con la experiencia en el territorio que lidera la Universidad de Ibagué, fiel a su eslogan: "Comprometidos con el desarrollo regional", en el que el patrimonio cultural es fundamental, como lo indica en su Plan Educativo Institucional (PEI), así: "La realización de programas y actividades culturales como elemento de la formación integral de la comunidad y como parte de su contribución al desarrollo social y a la conservación y fomento del patrimonio cultural del país" [Negrilla fuera de texto] (PEI, 2014, p. 7).

De acuerdo con estas premisas, el programa de Arquitectura y su cuerpo docente investigativo, encabezado por el doctor César Velandia, director del grupo de investigación Rastro Urbano, y el profesor Eduardo Peñaloza Kairuz, coordinador del Consultorio de Arquitectura del Norte del Tolima, decidieron adelantar desde los semilleros y los proyectos de investigación procesos inter y multidisciplinares en pro de la valoración y sostenibilidad de los recursos incalculables inmateriales y materiales de la región. De estas sinergias y en concordancia con otros programas como Ingeniería Civil, surgió el curso: "Construcción de infraestructuras menores y adecuaciones en viviendas en contextos rurales".

Gracias al apoyo de la Escuela Internacional de Verano, se vincularon al proceso los profesores Luis Palmero de la Universidad de Valencia, España, el profesor Jorge Olmedo 


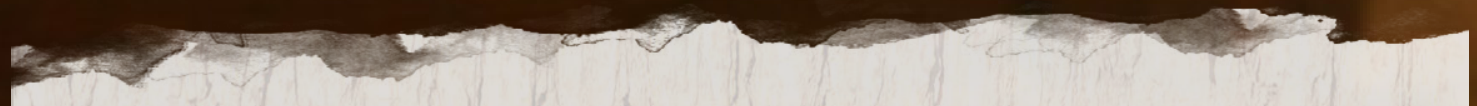

Montoya de Ingeniería Civil de Unibagué y el Consultorio de Arquitectura del Norte del Tolima. Uno de los objetivos principales del curso fue generar una reflexión frente a la infraestructura rural, la cual se ha visto amenazada por la pérdida del oficio y saberes ancestrales. Asimismo, el curso se enfocó en otros aspectos, entre los que se destacan:

- Formar puentes de trabajo colectivo entre las dos disciplinas, Ingeniería Civil y Arquitectura.

- Priorizar y formular soluciones prácticas desde la Ingeniería Civil y la Arquitectura, para la construcción y el desarrollo sostenible en contextos rurales vulnerables.

- Elaborar un proyecto para el beneficio de la comunidad.

- Diseñar los procesos técnicos necesarios para la construcción de tipologías rurales.

- Proyectar presupuestos de obra para construcciones rurales, de acuerdo con los materiales y los recursos disponibles en la región.

- Estudiar la viabilidad económica y la pertinencia de proyectos de desarrollo sostenible para los entornos rurales.

Finalmente, se lograron concretar los esfuerzos entre la academia, la comunidad y los organismos del Gobierno local y en dos días se articuló un ejercicio colectivo para el mejoramiento de las viviendas y el rescate patrimonial, mediante la intervención de una fachada deteriorada del Centro Histórico de Ambalema. El ejercicio contó con el apoyo y respaldo del Ministerio de Cultura, la Alcaldía de Ambalema, la Fundación Ambaviva y el programa Paz y Región de la Universidad, a través de la gestión realizada en campo con la estudiante.

Indagare tuvo la oportunidad de entrevistar al profesor Eduardo Peñaloza Kairuz, arquitecto egresado de la Universidad Pontificia Bolivariana de Medellín, con maestría en Tecnologías para el Control, Cálculo y la Ejecución en la Edificación, experto en manejo de oficinas de arquitectura y de estructuras en Barcelona, España, y en el diseño y construcción de proyectos arquitectónicos; profesor de tiempo completo del programa de Arquitectura de la Universidad de Ibagué, y quién lideró este Curso de Verano.

¿Qué objetivos maneja el Consultorio de Arquitectura en relación con el curso "Construcción de infraestructuras menores y adecuación de viviendas en contexto rural"?

Una de las misiones es articularnos entre programas, para así generar procesos conjuntos. Ahí es que se integra la carrera de Ingeniería Civil en el curso, porque sabemos que los 
arquitectos y los ingenieros civiles vamos a laborar en un medio compartido. Otra de las misiones es trabajar en procesos comunitarios, que estén enfocados en el tema de las costumbres y tradiciones, por eso el enfoque es el patrimonio cultural.

\section{¿Por qué se decide trabajar en el contexto rural?}

Colombia es en gran parte un país rural. Situaciones como la violencia y el conflicto armado han generado muy poco desarrollo en el campo. Nosotros, los arquitectos e ingenieros, desconocemos muchos procesos constructivos ancestrales, como la utilización del bahareque y la tapia. Pero el curso más que ir a revisar esos procesos, buscaba integrarlos en nuevas prácticas. Pensar en nuevas tecnologías para el futuro, a través del conocimiento de estas técnicas que se han ido olvidando.

Caso de ejemplo es el bahareque, que en el Tolima es muy recurrente. El bahareque es un sistema constructivo que permite llenar con tierra una serie de cañas o palos entretejidos, lo cual frena directamente las emisiones de dióxido de carbono. Para condiciones como las de Ambalema, funciona muy bien, porque la tierra tiene una composición que la convierte en buen aislante térmico, ideal para amortiguar los fuertes calores del Municipio.

\section{¿Qué diferencia hay entre las técnicas actuales y las ancestrales?}

Las técnicas que usamos nosotros en la ciudad y que replicamos en el campo no aportan al confort. Muchos de los proyectos llegan en satélite, los diseñan y los piensan para ciudades como Bogotá, y una vivienda de estas no puede ser igual en Ambalema. Estas propuestas escogen materiales fáciles y económicos de conseguir, como el cemento y el ladrillo, pero realmente no aportan a la comodidad de las personas. Y los saberes ancestrales que tienen en cuenta el entendimiento de condiciones como el clima, se han perdido porque ya nadie los utiliza.

¿De qué manera la utilización de materiales ancestrales aporta al medio ambiente y por consiguiente a reducir el cambio climático?

En el caso de la tierra, como lo comentaba anteriormente, es un material que si se extrae adecuadamente puede resolver muchos problemas de los cambios de temperaturas, como es el caso en los sistemas de cerramientos de las viviendas y, por ende, no usar otros procesos industriales que de por sí, para su fabricación, alteran el medio ambiente,

\section{6. como son el cemento, el concreto, etc.}

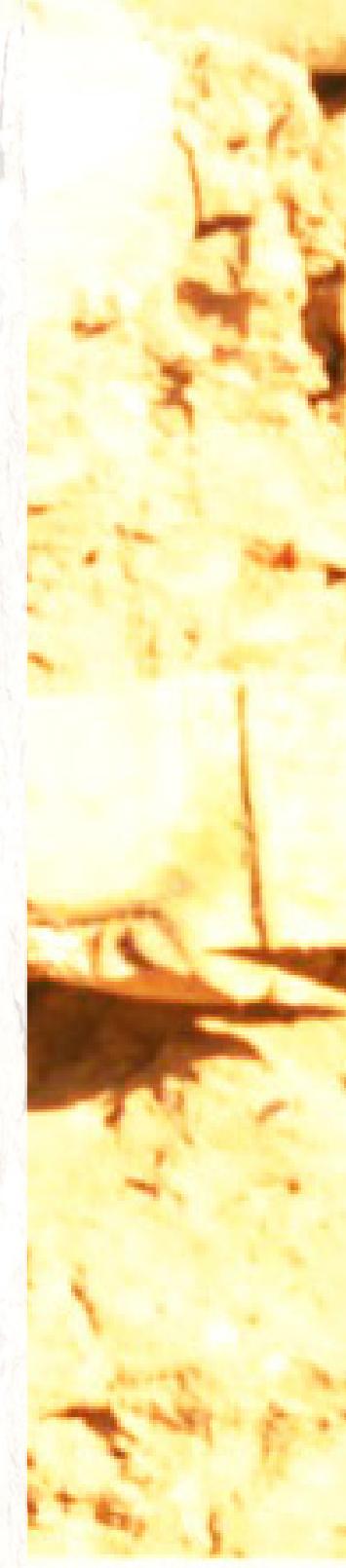


¿De qué serviría realizar restauraciones a las infraestructuras si con el tiempo se descuidan?

Una buena pregunta, la clave es pensar en reusar, ¿en cuál sería su nueva misión? No sirve para nada la restauración sin pensar en sus estrategias de sostenimiento en el tiempo y su razón de ser; como lo indica la pregunta, se caerían por su propio peso.

\section{¿Qué tan importantes son las infraestructuras en el patrimonio cultural?}

Son muy importantes, puesto que son las memorias físicas de un pueblo. Son los espacios que transmiten y comunican los procesos desde todas las dimensiones de una cultura.

\section{¿Cómo lograr que las nuevas generaciones se interesen por el patrimonio cultural?}

Acercándolos y buscar maneras lúdicas de verlo. Pensar en estrategias que no indiquen que se resaltan solo por hechos nostálgicos, sino que son claves para entender quiénes somos y para dónde vamos.

"Construcción de infraestructuras menores y adecuación de viviendas en contexto rural" es tan solo uno de los cursos que la Universidad de Ibagué ofrece en la Escuela de Verano, con el fin de acercar a los estudiantes, profesores de la Universidad, invitados nacionales e internacionales, para que analicen y reflexionen sobre temas regionales como parte del compromiso con el desarrollo de la región. De esta manera, se extiende la invitación para que en próximas oportunidades decidan ser parte de estos proyectos de gran incidencia e importancia en el Departamento.

\section{Referencias}

Universidad de Ibagué (2014). Plan Educativo Institucional (PEI). Ibagué, Colombia: Unibagué. Recuperado de https://hdl.handle.net/20.500.12313/369

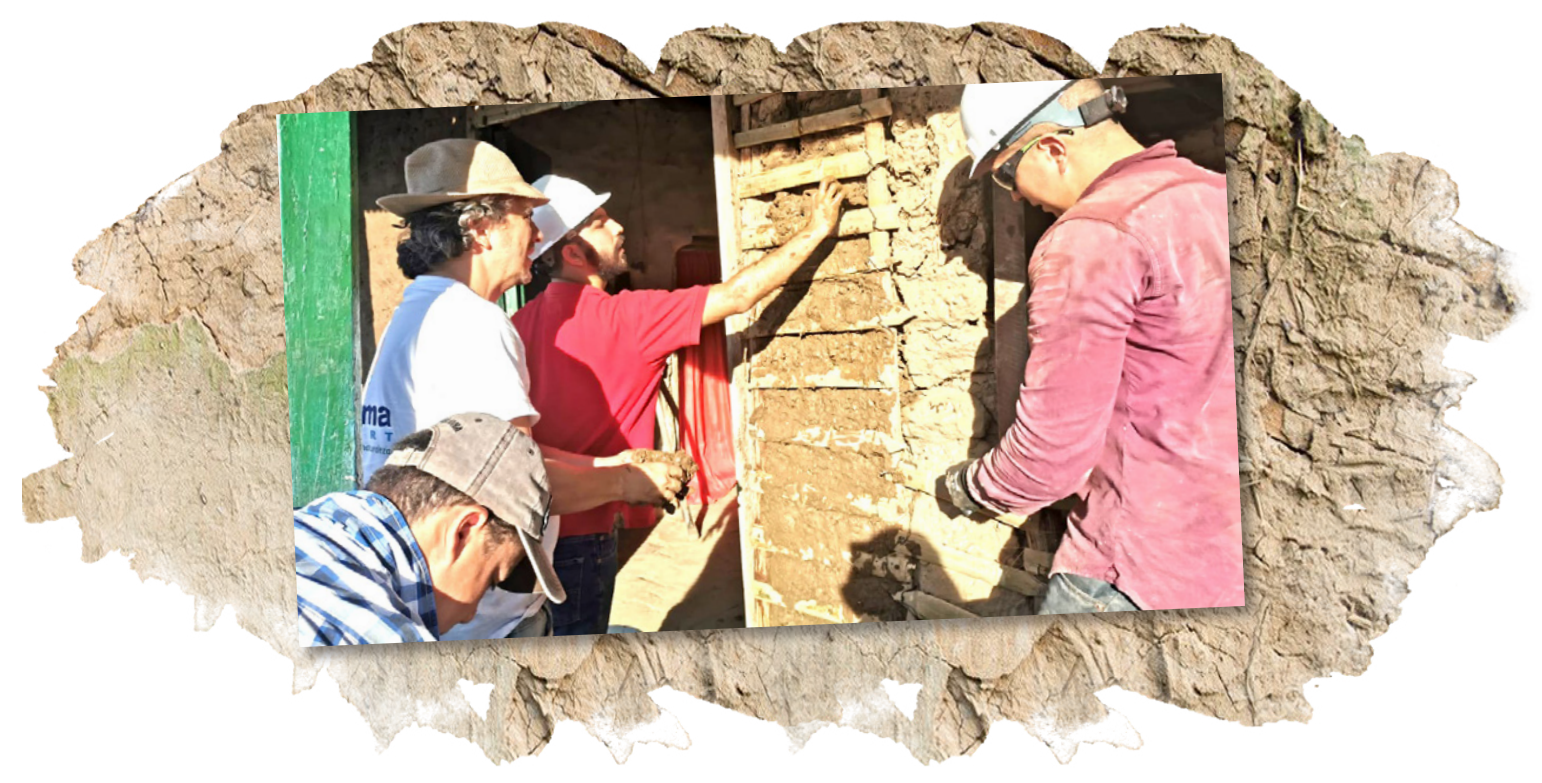

